\title{
Cryptosphaeria Dieback of Fremont Cottonwood Caused by Cryptosphaeria pullmanensis and C. multicontinentalis in California
}

\author{
F. P. Trouillas and W. D. Gubler, Department of Plant Pathology, University of California, Davis 95616
}

\begin{abstract}
Trouillas, F. P., and Gubler, W. D. 2016. Cryptosphaeria dieback of Fremont cottonwood caused by Cryptosphaeria pullmanensis and C. multicontinentalis in California. Plant Dis. 100:777-783.

Fremont cottonwood is a large and tall tree native to riparian areas in the southwestern United States. It grows along streams, rivers, and wetlands and serves many ecological and socioeconomic functions. In recent years, we observed a severe decline of Fremont cottonwood trees in California. Trees showed branches dying back, with dark-brown internal discoloration and decay of the wood of twigs, branches, or trunks. Eventually, the cambium and the bark were killed, causing a canker. The fungus Cryptosphaeria pullmanensis was isolated consistently from the necrotic wood of

branches and twigs. On rare occasion, $C$. multicontinentalis was also isolated from symptomatic wood. Therefore, we investigated the pathogenicity in Fremont cottonwood of C. pullmanensis and C. multicontinentalis. Koch's postulates were completed in saplings and both species appeared highly virulent, producing internal necrosis and staining of the wood. This study is the first to report Cryptosphaeria dieback of Populus fremontii caused by $C$. pullmanensis and C. multicontinentalis. Symptoms and signs of this new disease are described and illustrated.
\end{abstract}

Fremont cottonwood (Populus fremontii S. Watson) is native to the southwestern United States and occurs mostly in riparian habitats from western Texas through New Mexico, Arizona, California, Nevada, and Utah. It is distributed throughout California and is largely present in the San Joaquin and Sacramento Valleys. Fremont cottonwood trees are found mainly near water and usually dominate the riparian forests and the immediate stream banks at elevations less than 2,000 $\mathrm{m}$ (Hickman 1993). Fremont cottonwood is a key riparian species, providing various ecosystem functions such as erosion prevention, bank and sediment stabilization, and food, shelter, and nesting sites for many migratory and resident bird species (Hansen et al. 1988; Laymon 1984; Platts et al. 1987; Stevens et al. 1977). Fremont cottonwood is cultivated as an ornamental tree and restoration tree of riparian zones. It is generally well suited for revegetating riparian sites and it has been used widely in riparian rehabilitation projects (Platts et al. 1987). It has also been broadly planted as an ornamental tree and shade tree and used as a windbreak throughout the southwestern United States (Johnson and Lowe 1985; Lanner 1983).

Despite the importance of Fremont cottonwood in its native habitats and the numerous efforts to reintroduce this species in previously disturbed environments (Harris 1999), little is known about diseases affecting its health and survival. Most common diseases of poplar and cottonwood trees in North America have included Leucostoma and Valsa cankers (also known as Cytospora canker) caused by the fungi Leucostoma niveum and Valsa sordida, respectively (Sinclair and Lyon 2005). These fungi are capable of producing cankers, usually with irregular margins, in trunks, limbs, and small branches. Another widespread disease of poplar is Cryptosphaeria canker, occurring primarily on trembling aspen (P. tremuloides Michx.) across North America (Hinds 1981; Hinds and Laurent 1978). This disease is caused by the fungus Cryptosphaeria lignyota (Fr.) Auersw. and it is known to cause branch, sprout, and sapling mortality; trunk cankers; and discoloration and decay of aspen stems (Hinds 1981; Hinds and Laurent 1978). With Cryptosphaeria canker, cankers usually originate at trunk wounds and elongate along the stem. The fungus colonizes the heartwood and sapwood and

Corresponding author: F. P. Trouillas; E-mail: flotrouillas@ucdavis.edu

Accepted for publication 3 November 2015.

http://dx.doi.org/10.1094/PDIS-09-15-0972-RE

(C) 2016 The American Phytopathological Society then penetrates the cambium and bark, causing the canker (Hinds 1981). The bark is killed and adheres firmly to the wood (Hinds 1981).

In a recent survey for Cryptosphaeria spp. occurring in the western United States, we observed a severe decline of Fremont cottonwood trees in California (Trouillas et al. 2015). Symptoms on trees were characterized by branch dieback and dark-brown, internal discoloration and decay of the wood of infected twigs, limbs, and trunks. As the disease developed, the cambium as well as the bark was killed, causing a canker. Isolations from the symptomatic wood of Fremont cottonwood trees in California and subsequent taxonomic studies allowed the identification of $C$. pullmanensis Glawe as well as C. multicontinentalis Trouillas, F. Peduto, Inderb. \& Gubler (Trouillas et al. 2015). The widespread decline of Fremont cottonwood trees in California and the common occurrence of Cryptosphaeria spp. in the wood of diseased trees have raised new concerns regarding this plant's health. Accordingly, we questioned the ability of these newly reported Cryptosphaeria spp. to cause disease to their host Fremont cottonwood. This study investigates the pathogenicity of C. pullmanensis and C. multicontinentalis in Fremont cottonwood and illustrates the new disease Cryptosphaeria dieback of Fremont cottonwood.

\section{Materials and Methods}

Origin of isolates. In total, 12 isolates, including 7 isolates of $C$. pullmanensis and 5 isolates of $C$. multicontinentalis, were used for this study (Table 1). Isolates originated from wood necroses or perithecia collected on $P$. fremontii and $P$. balsamifera L. subsp. trichocarpa (Torr. \& A. Gray ex Hook.) Brayshaw and were previously identified and characterized by Trouillas et al. (2015). Isolates were cultured onto petri dishes filled with potato dextrose agar (PDA; Difco Laboratories, Detroit) amended with tetracycline at $100 \mathrm{ppm}$ (PDA-tet) and prepared for this study by incubating them for 10 days at $25^{\circ} \mathrm{C}$.

Pathogenicity tests. Two pathogenicity trials were conducted in a shade house at the University of California, Davis, using 2-year-old saplings of $P$. fremontii planted in 1 gal. plastic pots. Tests were conducted to determine the ability of these fungi to colonize the wood and cause discoloration and decay in freshly wounded stems of young cottonwood trees.

In the first experiment, five isolates were inoculated on 26 December 2005 using five tree replicates. Treatments consisted of three isolates of C. pullmanensis (HBPF13, HBPF15, and DPOP100), two isolates of $C$. multicontinentalis (HBPF7 and HBPF8), and a control. 
Stems were wounded using a 5-mm cork borer and wounds were inoculated using 5-mm plugs of fresh mycelium grown on PDA-tet medium. The control trees were inoculated with sterile blank plugs of PDA-tet. All wounds were then sealed with petroleum jelly and wrapped with Parafilm. After 1 year, the wood of inoculated plants was inspected for discoloration and disruption of the xylem. The bark was peeled off and the length of brown discoloration extending in the xylem from the point of inoculation, both acropetally and basipetally, was measured. Stems were then surface sterilized by flaming and fragments of symptomatic xylem tissue were cultured on PDA-tet in an attempt to recover fungal isolates and complete Koch's postulates. Effective recoveries of Cryptosphaeria spp. were confirmed by observation of the unique colony size, shape, and color characteristics of each species (Trouillas et al. 2015).

A second experiment was performed using a similar approach on 3 April 2007. In this test, in total, 11 Cryptosphaeria isolates were inoculated on 2-year-old saplings using six replications per fungal isolates. Treatments included six isolates of C. pullmanensis (HBPF13, DWIN200, DPOP100, DMERC100, JOSH1, and PBW10), five isolates $C$. multicontinentalis (HBPF1, HBPF7, HBPF8, DSIERRA200, and DSIERRA600), and a control. Sterile blank plugs of PDA-tet were used as controls. Wood inspection and reisolations were conducted as described above 14 months following inoculation of isolates.

Statistical analyses were performed using analysis of variance (ANOVA) in SAS (version 9.1.3; SAS Institute, Cary, NC). Log transformations were performed to reduce heteroscedasticity. Dunnett's $t$ test was used to assess significant differences in the extent of vascular discoloration between the control group mean and the remaining treatment group means.

\section{Results}

Symptoms and signs. External symptoms of Cryptosphaeria dieback of Fremont cottonwood appeared as branch dieback (Fig. 1A). Necrosis and decay occurred in both sapwood and heartwood, usually originating from the heartwood and slowly developing into the sapwood. As the disease progressed, the fungus grew out from the wood, killing the cambium and bark and ultimately forming a canker. Symptoms in the wood consisted of dark-brown regions commonly associated with orange staining (Fig. 1B).

Signs of Cryptosphaeria dieback of Fremont cottonwood included reddish to orange conidial cirrhi produced by $C$. pullmanensis on infected Fremont cottonwood trees (Figs. 1C and D and 2A and B). Also, Cryptosphaeria dieback was almost constantly associated with the presence of perithecia of $C$. pullmanensis on the surface of the bark of branches and twigs, and recognizable by the slightly and separately emerging ostioles (Fig. 2C and D). Perithecia or conidiomata of $C$. multicontinentalis were not found on $P$. fremontii, which concurs with the limited incidence of isolation of this fungus from symptomatic wood tissue. Cryptosphaeria dieback of Fremont cottonwood was observed in all counties visited in California, including Napa, Sonoma, Solano, Merced, Sacramento, Yolo, Stanislaus, and El Dorado (Trouillas et al. 2015). C. pullmanensis was the main fungus isolated from 40 diseased branches or twigs collected from different trees across the various counties. On the other hand, $C$. multicontinentalis was only isolated from a few branches showing dieback collected on trees in Sonoma County.

Pathogenicity tests. Results of the two pathogenicity tests showed that $C$. pullmanensis and $C$. multicontinentalis were pathogenic to Fremont cottonwood. Both fungi produced dark-brown discoloration of the xylem (Fig. 3A to F) and were recovered from $100 \%$ of all inoculated saplings after 12- and 14-month incubation periods. In the first experiment, the extent of vascular discoloration varied from 58 to $93 \mathrm{~mm}$ for inoculations with C. multicontinentalis and from 50.6 to $63 \mathrm{~mm}$ for inoculations with C. pullmanensis (Fig. 4A). In the control, the dark-brown discolorations associated with the disease were absent. Instead, the wood of control plants showed a lightcolored staining that averaged $22 \mathrm{~mm}$ in length (Fig. 4A) and no fungi were isolated from this staining. ANOVA of the transformed data set showed significant differences (at $\alpha=0.05$ ) among fungal treatments $(P=0.0004)$. The Dunnett's $t$ test showed significant differences of length of vascular discoloration between treatments with Cryptosphaeria isolates and the control (Fig. 4A).

In the second experiment, the extent of wood discoloration varied from 64.3 and $104.2 \mathrm{~mm}$ for inoculations with $C$. multicontinentalis and from $50 \mathrm{~mm}$ to $96.7 \mathrm{~mm}$ for inoculations with C. pullmanensis (Fig. 4B). Average length of staining in the control was $29.4 \mathrm{~mm}$ (Fig. 4B). ANOVA of the transformed data set showed significant differences (at $\alpha=0.05)$ among the treatments $(P<0.0001)$. The Dunnett's $t$ test showed significant differences between treatments with Cryptosphaeria isolates and the control.

\section{Discussion}

Although Cryptosphaeria canker of trembling aspen caused by C. lignyota has been largely studied (Hinds 1981; Hinds and Laurent 1978), this work constitutes the first report of Cryptosphaeria dieback of Fremont cottonwood (P. fremontii) caused by C. pullmanensis and C. multicontinentalis. Cryptosphaeria dieback of Fremont cottonwood is characterized by twig and branch dieback with internal dark-brown discoloration and orange staining of the wood. Based on field observation, trees infected with Cryptosphaeria dieback may die entirely.

C. pullmanensis was found to be widespread throughout the natural distribution of $P$. fremontii in the western United States. Perithecia of $C$. pullmanensis together with symptoms of the disease were detected in nearly all $P$. fremontii stands visited in the western United States (Trouillas et al. 2015). In California, C. pullmanensis was the most prevalent fungal species associated with branch dieback of Fremont cottonwood trees in Napa, Sonoma, Solano, Merced, Sacramento, Yolo, Stanislaus, and El Dorado Counties. On the other

Table 1. Isolates collected for this study and used in the pathogenicity studies

\begin{tabular}{|c|c|c|c|c|c|}
\hline Fungal species & Collection number & Host & Origin $^{\mathbf{a}}$ & Collector or isolator ${ }^{b}$ & Accession $^{\mathrm{c}}$ \\
\hline Cryptosphaeria multicontinentalis & HBPF1 & Populus fremontii & Sonoma & Trouillas & KT425176 \\
\hline C. multicontinentalis & HBPF7 & P. fremontii & Sonoma & Trouillas & KT425177 \\
\hline C. multicontinentalis & HBPF8 & P. fremontii & Sonoma & Trouillas & KT425178 \\
\hline C. multicontinentalis & DSIERRA200 & P. balsamifera subsp. trichocarpa & Sierra & Trouillas & KT425180 \\
\hline C. multicontinentalis & DSIERRA600 & P. balsamifera subsp. trichocarpa & Sierra & Trouillas & KT425184 \\
\hline C. pullmanensis & HBPF15 & P. fremontii & Sonoma & Trouillas & KT425197 \\
\hline C. pullmanensis & DPOP100 & P. fremontii & Sonoma & Trouillas & KT425194 \\
\hline C. pullmanensis & DWIN200 & P. fremontii & Solano & Trouillas & KT425196 \\
\hline C. pullmanensis & DMERC100 & P. fremontii & Merced & Trouillas & KT425205 \\
\hline C. pullmanensis & JOSH1 & P. fremontii & Riverside & Trouillas & KT425224 \\
\hline C. pullmanensis & PBW10 & P. fremontii & Solano & Trouillas & KT425210 \\
\hline C. pullmanensis & HBPF13 & P. fremontii & Sonoma & Trouillas & $\ldots$ \\
\hline
\end{tabular}

a Counties in California in the United States.

b Florent Trouillas.

c Internal transcribed spacer ribosomal DNA GenBank accession number. 
hand, C. multicontinentalis was found only in a few branches in $P$. fremontii trees showing dieback in Sonoma County. Also, no reproductive structures (perithecia or conidiomata) of $C$. multicontinentalis were found on $P$. fremontii. As reported by Trouillas et al. (2015),
C. multicontinentalis occurred primarily on black cottonwood ( $P$. balsamifera subsp. trichocarpa) in the Sierra Nevada and in the central coast of California. The same authors also have observed some degree of host specificity or host preference among Cryptosphaeria
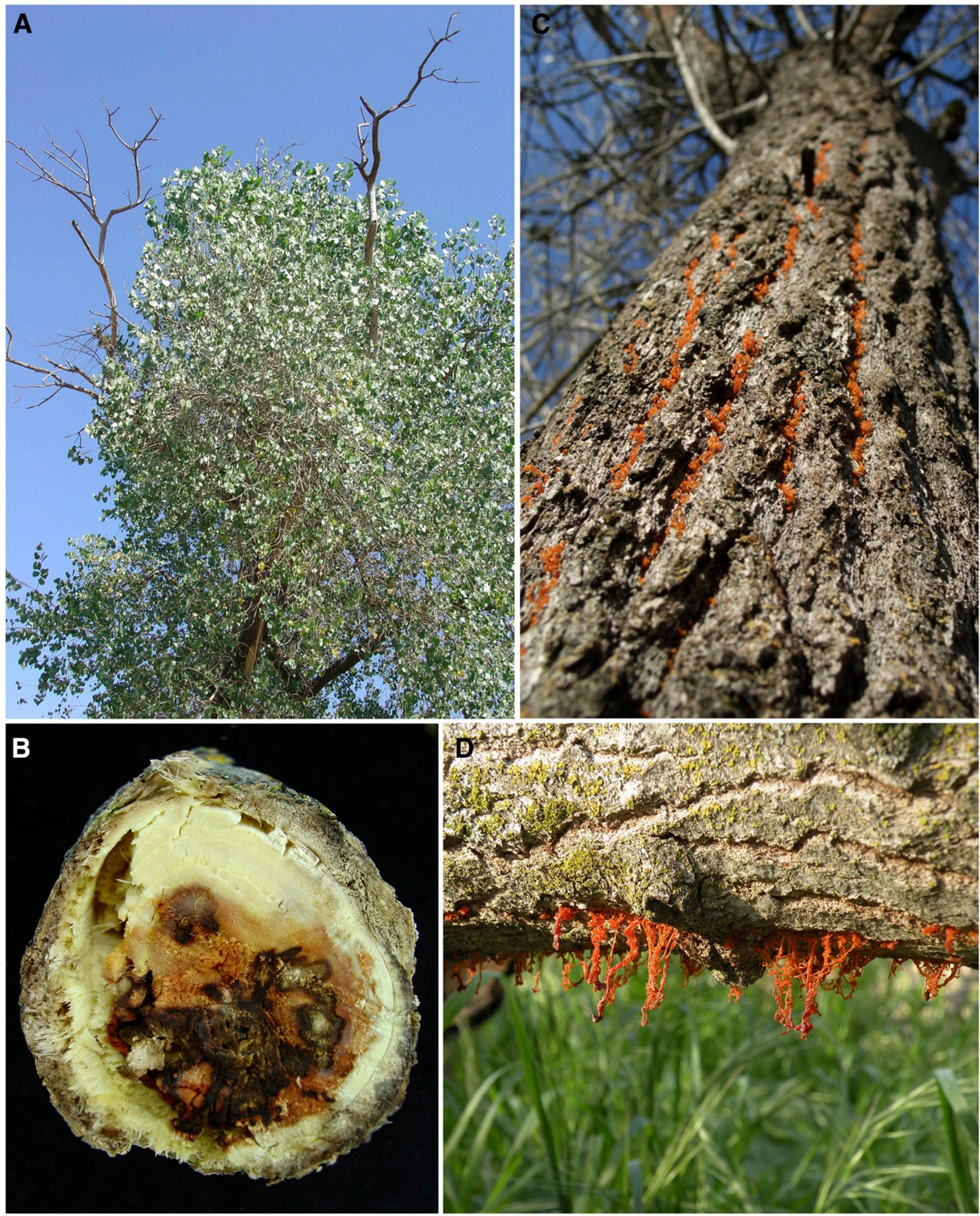

Fig. 1. Symptoms and signs of Cryptosphaeria dieback of Fremont cottonwood. A, Branch dieback; B, transversal view in branch of an active canker and decay; and C and D, typical reddish-orange conidial masses of Cryptosphaeria pullmanensis exuding through natural bark cracks. 
spp. and hypothesized the possibility of coevolution of these fungi with their Salicaceae host plants (Trouillas et al. 2015). The preferred hosts for $C$. multicontinentalis and $C$. pullmanensis (i.e., $P$. balsamifera subsp. trichocarpa and $P$. fremontii, respectively) occupy different habitats and geographic ranges, which could explain why C. multicontinentalis is less common on P. fremontii. Nevertheless, in this study, both species were found to be pathogenic to $P$. fremontii. On occasion, $C$. pullmanensis was also isolated from other ornamental cottonwood species, including $P$. nigra (Lombardy poplar) and $P$. deltoides (Eastern cottonwood) showing symptoms of the disease (Trouillas et al. 2015), and it is expected, although not yet proven, to be pathogenic to these hosts. Previous work also has shown the pathogenicity of $C$. pullmanensis in grapevines and its capacity to cause cankers (Trouillas and Gubler 2010). As with C. lignyota,
C. pullmanensis colonizes the heartwood and sapwood and can ultimately invade the cambium and bark, causing canker.

Symptoms and signs of Cryptosphaeria dieback of Fremont cottonwood closely resembled Cytospora canker of poplar caused by $V$. sordida (syn. Cytospora chrysosperma) (Sinclair and Lyon 2005). Particularly, the reddish-orange conidial masses or cirrhi produced by $C$. pullmanensis on infected Fremont cottonwood trees (Fig. 1C and D) are similar to those produced by C. chrysosperma, suggesting that the two diseases may be frequently confused. Moreover, conidiomata of $C$. pullmanensis also resemble the form-genus Cytospora Ehrenb.:Fr (Glawe 1984) (Fig. 2A and B). However, C. pullmanensis can be distinguished from the formerly documented C. chrysosperma by having much longer and larger conidia (Glawe 1984; Trouillas et al. 2010). The resemblance between the two
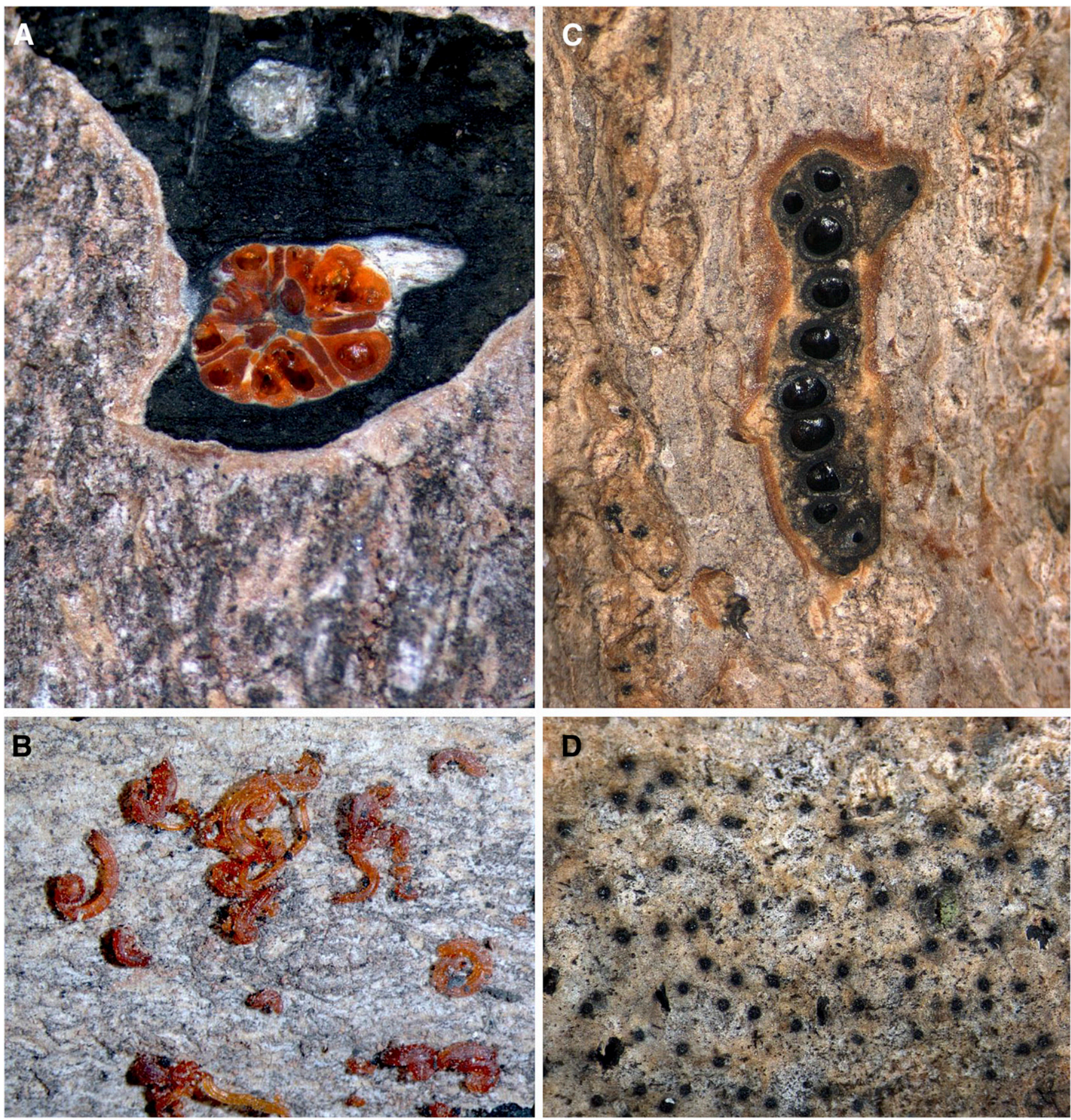

Fig. 2. Morphology of the anamorph and teleomorph of Cryptosphaeria pullmanensis in the bark of Populus fremontii. A, Transverse section through conidiomata; B, reddish to orange conidial cirrhi; C, transverse section through perithecial cavities; and D, slightly and separately emerging perithecial ostioles. 


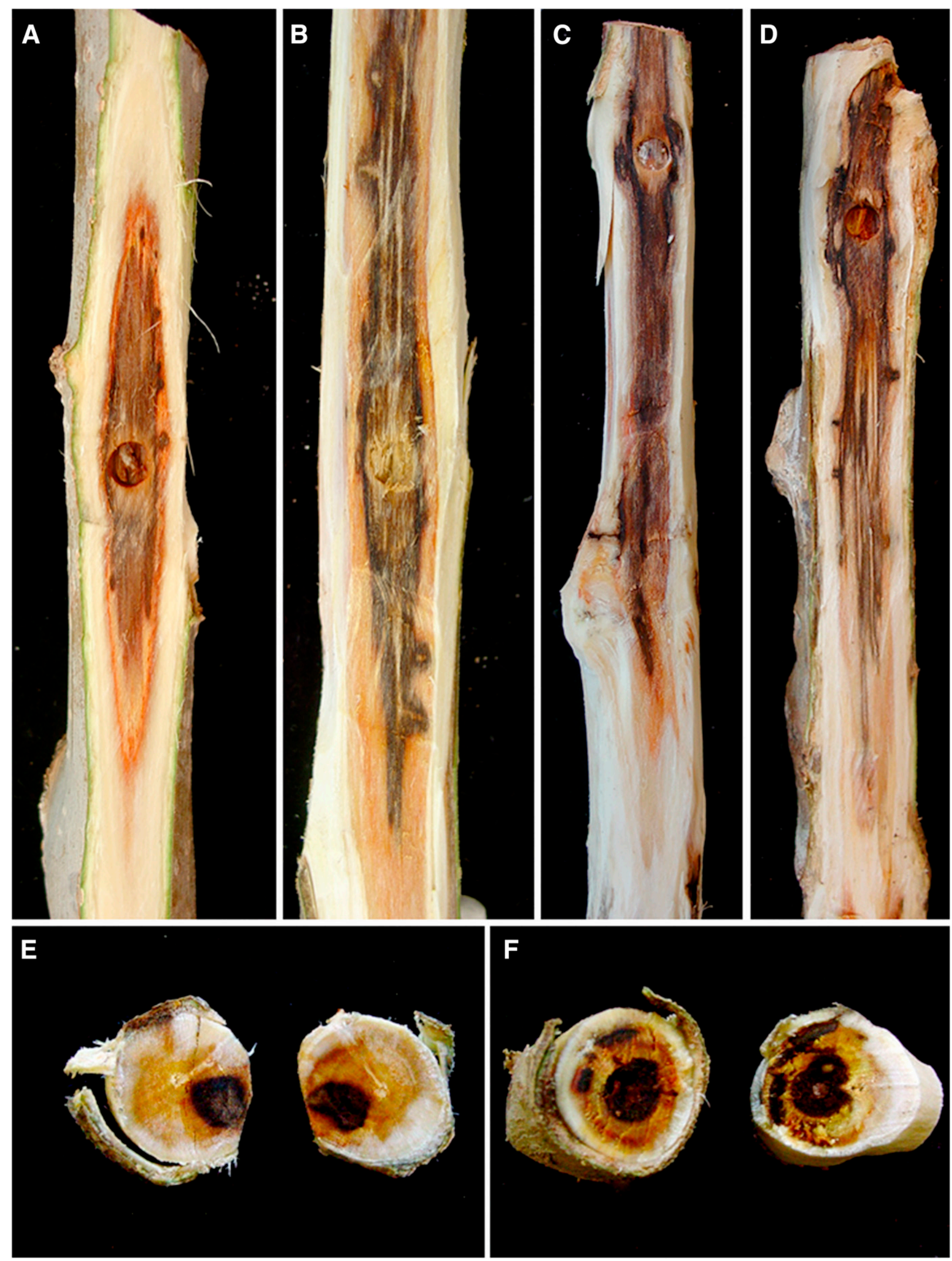

Fig. 3. Symptoms in stems of Fremont cottonwood saplings produced 12 to 14 months after inoculation by various Cryptosphaeria isolates. Stems were wounded using a 5-mm cork borer and wounds were inoculated using 5-mm plugs of fresh mycelium grown on agar medium. A, Longitudinal section of stem inoculated with Cryptosphaeria pullmanensis isolate DPOP100 and B, isolate HBPF13; C, longitudinal section of stem inoculated with C. multicontinentalis isolate HBPF7 and D, isolate HBPF8. E, Transverse section of stem inoculated with C. pullmanensis isolate DMERC100 and F, C. multicontinentalis isolate DSIERRA600. 
A

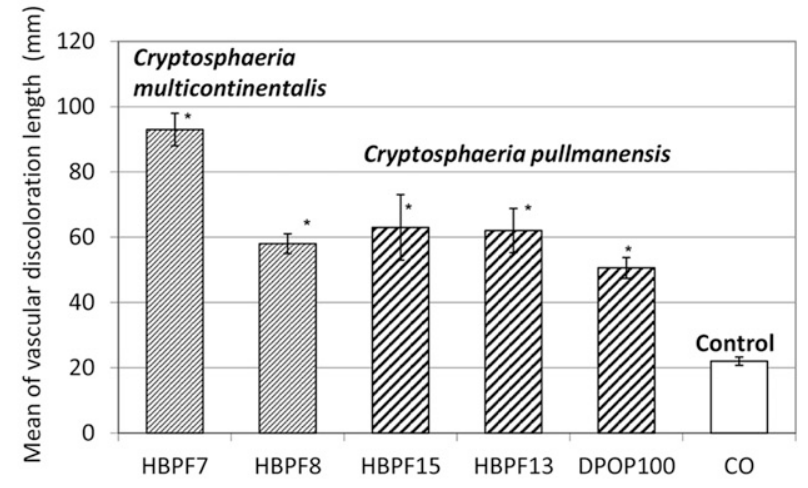

B

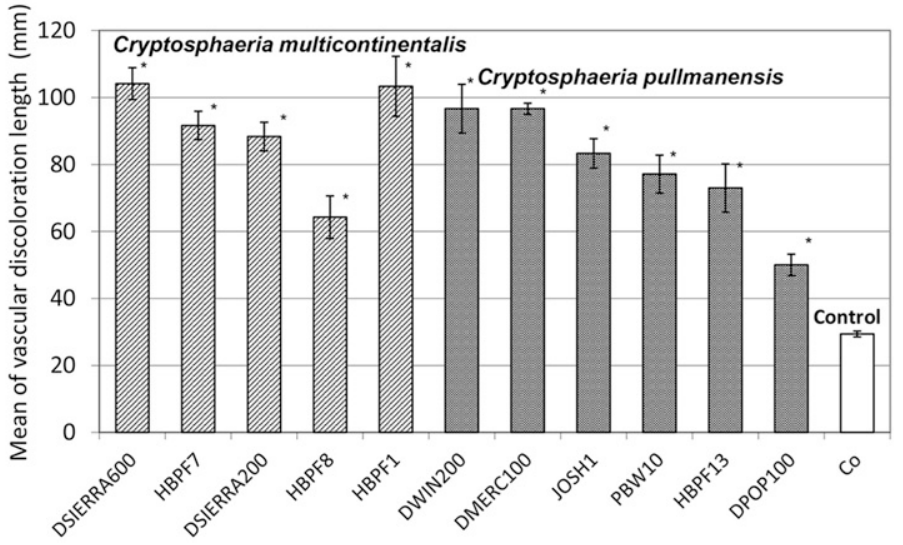

Fig. 4. Mean of vascular discoloration length A, 12 months and B, 14 months after inoculation of various Cryptosphaeria isolates in Fremont cottonwood saplings inoculated in a shade house using 5 -mm plugs of fresh mycelium grown on agar medium. Asterisks $\left(^{*}\right)$ indicate that average length of vascular discolorations was significantly different from the agar-only inoculated control according to Dunnett's $t$ test $(\mathrm{A}, P=0.0004$ and $\mathrm{B}, P<0.0001)$. Bars represent standard error of the mean.

diseases and their respective causal agents also could explain why this new disease of Fremont cottonwood has been overlooked thus far. On the other hand, C. multicontinentalis closely resembles in morphology its sister species, C. lignyota (Trouillas et al. 2015). Both species occur in similar habitats in high-altitude forests and it is likely that $C$. multicontinentalis also has been overlooked in previous attempts to identify the causal agent of Cryptosphaeria canker of aspen.

As with most pyrenomycetous fungi, spores of these new pathogens may be released during rain events and carried to new infection sites by wind, rain, or insects. Infection may occur through natural wounds and injuries caused by insects and birds. Both the conidia and ascospores of $C$. pullmanensis can germinate easily on PDA medium, suggesting that both spore types may contribute to infections. The asexual and sexual states of C. pullmanensis occurred commonly in the bark of dead or decaying Fremont cottonwood trees, thus serving as natural inoculum sources.

The recent detection of Cryptosphaeria dieback on Fremont cottonwood suggests a deviation from historical records and raises questions regarding the health of riparian forests. The extensive spread of $C$. pullmanensis throughout the native range of $P$. fremontii (Trouillas et al. 2015) also could compromise the persistence of Fremont cottonwood in its natural habitat as well as the success of restorative plantations. It has been acknowledged that various environmental stress factors have been contributing to the decline of cottonwood and aspen (Populus spp.) in many parts of North America (Rood et al. 1995, Worrall et al. 2008, 2010, 2013). Common stress factors include lowered water tables, increased sedimentation, moisture stress, the rising of temperatures, and intensification of drought. Tree decline can be correlated, in part, with an increase of the host susceptibility to plant pathogens following drought stress (Guyon and Hoffman 2011). It also has been suggested that fungal pathogens play an important role in decline episodes of aspen because they may intensify or prolong the effects of moisture stress (Worrall et al. 2013). Severely affected aspen stands have shown poor regeneration potential, raising concerns that increasing drought could eventually lead to extensive loss of aspen forest cover (Worrall et al. 2013). Studies on Cytospora canker of aspen have shown that larger cankers formed on drought-stressed aspen than on nonstressed trees (Guyon et al. 1996). Similarly, Bloomberg (1962) revealed that aspen and cottonwood trees were not susceptible unless they experience substantial drop of water potential. For these reasons, we hypothesized that recent changes in California weather patterns, including the intensification of drought, lowered water tables, eliminated natural flooding in the native habitats of cottonwood, and the general intensification of agriculture, may have encouraged this new disease to develop.

\section{Acknowledgments}

We thank the American Vineyard Foundation and the Viticulture Consortium West for financial support.

\section{Literature Cited}

Bloomberg, W. J. 1962. Cytospora canker of poplars: Factors influencing the development of the disease. Can. J. Bot. 40:1271-1280.

Glawe, D. A. 1984. Cryptosphaeria pullmanensis, a new species from Washington state. Mycologia 76:166-169.

Guyon, J., and Hoffman, J. T., 2011. Survey of Aspen Disease in the Intermountain Region. Online publication. U. S. Dep. Agric. For. Serv. State and Private Forestry, Forest Health Protection, Intermountain Region. R4-OFO Report 11-01.

Guyon, J. C., Jacobi, W. R., and McIntyre, G. A. 1996. Effect on environmental stress on the development of Cytospora canker of Aspen. Plant Dis. 80: 1320-1326.

Hansen, P., Chadde, S., Pfister, R., Joy, J., Svoboda, D., Pierce, J., and Myers, L. 1988. Riparian Site Types, Habitat Types, and Community Types of Southwestern Montana. University of Montana, School of Forestry, Montana Riparian Association, Missoula.

Harris, R. R. 1999. Defining reference conditions for restoration of riparian plant communities: Examples from California, USA. Environ. Manage. 24: $55-63$.

Hickman, J. C. 1993. The Jepson Manual. Higher Plants of California. University of California Press, Berkeley.

Hinds, T. E. 1981. Cryptosphaeria canker and Libertella decay of aspen. Phytopathology 71:1137-1145.

Hinds, T. E., and Laurent, T. H. 1978. Common aspen diseases found in Alaska. Plant Dis. Rep. 62:972-975.

Johnson, R. R., and Lowe, C. W. 1985. On the development of riparian ecology Pages 112-116 in: Riparian Ecosystems and Their Management: Reconciling Conflicting Uses. R. R. Johnson, C. D. Ziebell, D. R. Patten, P. F. Ffolliott, and R. H. Hamre, eds. Gen. Tech. Rep. RM-120. U.S. Forest Service, Fort Collins, CO.

Lanner, R. M. 1983. Trees of the Great Basin: A Natural History. University of Nevada Press, Reno.

Laymon, S. A. 1984. Riparian bird community structure and dynamics: Dog Island, Red Bluff, California. Pages 587-597 in: California Riparian Systems: Ecology, Conservation, and Productive Management. R. E. Warner and K. Hendrix, eds. University of California Press, Berkeley.

Platts, W. S., Armour, C. L., Booth, G. D., Bryant, M., Bufford, J. L., Cuplin, P., Jensen, S., Lienkaemper, G. W., Minshall, G. W., Monsen, S. T., Nelson, R. L., Sedell, J. R., and Tuhy, J. S. 1987. Methods for Evaluating Riparian Habitats with Applications to Management. U. S. Dep. Agric. For. Serv. Gen. Tech. Rep. INT-221, Ogden, UT.

Rood, S. B., Mahoney, J. M., Reid, D. E., and Zilm, L. 1995. Instream flows and the decline of riparian cottonwoods along the St. Mary River, Alberta. Can. J. Bot. 73:1250-1260.

Sinclair, W. A., and Lyon, H. H. 2005. Page 659 in: Diseases of Trees and Shrubs, 2nd ed. Cornell University Press, Ithaca, NY.

Stevens, L. E., Brown, B. T., Simpson, J. M., and Johnson, R. R. 1977. The importance of riparian habitat to migrating birds. Pages 156-164 in: Importance, Preservation and Management of Riparian Habitat: A Symposium. U. S. Dep. Agric. For. Serv. Gen. Tech. Rep. RM-43. R. R. Johnson and D. A. Jones, eds. Rocky Mountain Forest and Range Experiment Station, Fort Collins, CO.

Trouillas, F. P., and Gubler, W. D. 2010. Pathogenicity of Diatrypaceae species in grapevines in California. Plant Dis. 94:867-872.

Trouillas, F. P., Peduto Hand, F., Inderbitzin, P., and Gubler, W. D. 2015. The genus Cryptosphaeria in the western United States: Multi-locus phylogeny, taxonomy and a new species, C. multicontinentalis. Mycologia 107:1304-1313. 
Trouillas, F. P., Urbez-Torres, J. R., and Gubler, W. D. 2010. Diversity of diatrypaceous fungi associated with grapevine canker diseases in California. Mycologia 102:319-336.

Worrall, J. J., Egeland, L., Eager, T., Mask, R. A., Johnson, E. W., Kemp, P. A., and Shepperd, W. D. 2008. Rapid mortality of Populus tremuloides in southwestern Colorado, USA. For. Ecol. Manage. 255:686-696.
Worrall, J. J., Marchetti, S. B., Egeland, L., Mask, R. A., Eager, T., and Howell, B. 2010. Effects and etiology of sudden aspen decline in southwestern Colorado, USA. For. Ecol. Manage. 260:638-648.

Worrall, J. J., Rehfeldt, G. E., Hamann, A., Hogg, E. H., Marchetti, S. B., Michaelian, M., and Gray, L. K. 2013. Recent declines of Populus tremuloides in North America linked to climate. For. Ecol. Manage. 299:35-51. 